\title{
Project Management in Education: A Case Study for Student Learning Pathway Evaluation in a Lifelong Learning Program Using Fuzzy CPM and Fuzzy PERT
}

\author{
Omiros Iatrellis, $M S c$ \\ Panos Fitsilis, PhD \\ Dimitrios Lampakis, PhD \\ University of Thessaly, Larissa, Greece \\ Achilles Kameas, PhD \\ Hellenic Open University Patras, Greece
}

\begin{abstract}
Time to degree and graduation are paramount concerns in higher education today and have caught the attention of educators, policy makers, and researchers in recent years. Delays in student flow through learning pathways may result in undesired consequences and this fact has made educators and the public start to regard timely degree completion as a critical measure of accountability for colleges and universities. Project management is defined as application of techniques to project activities to meet the project requirements. It has techniques that can help Higher Educational Institutions (HEIs) standardize education and quality, reduce costs, improve effectiveness and decrease prolonged education periods. The current study is carried out in a University's Division of Lifelong Learning to understand the student flow of the offered program with respect to the Fuzzy Critical Path Method (FCPM) and Fuzzy Program Evaluation Review Technique (FPERT). The reason for incorporating fuzzy sets is stemmed from that fuzzy numbers are more effective for high uncertainty processes as in learning environments. Activities affecting student flow through the learning pathways are identified and project network is drawn. 72 student' data about the times of each activities are obtained from the observed university. Findings through application of FCPM and FPERT, the expected time for completion of the project, slack times and the critical path are determined.
\end{abstract}

Keywords: Education, lifelong learning, time to degree, fuzzy critical path method, fuzzy program evaluation review technique. 


\section{Introduction:}

A project can be considered to be the achievement of a specific objective, which involves a series of activities and tasks and it has to be completed within a set specification, having definite start and end dates (Munns \& Bjeirmi, 1996). A standard project typically has the following four major phases each with its own agenda of tasks and issues: initiation, planning, implementing and completion processes (Serrano \& Avilés, 2018). Planning the project is a critical phase of the lifecycle of a project, as defined processes and tasks can predetermine efficiency. Project management is the practice of initiating, planning, executing, controlling, and closing the work of a team to achieve specific goals and meet specific success criteria at the specified time. In its Glossary, A Guide to the Project Management Body of Knowledge (Project Management Institute Inc, 2000) defines the Triple Constraint which in the basic setup is the time, cost and scope with quality occasionally included as an adjunct to or substitute for scope or as a fourth constraint. In education the notion of an iron triangle has been posited, linking firstly access, quality and cost and latterly accessibility, quality and efficiency in order to help explain the interplay and interactions between specified components of higher education systems at different levels and to take account of emerging trends towards new approaches (Lane, 2014). Quality, one of the most important of all, is directly related to the efficiency and performance in all the facets of education sector (Iatrellis, Kameas. Achilles, \& Panos, 2019). An important factor that affects the performance of educational processes in a HEI is the "Time to completion" or "Time to degree", which refers to the time it takes for a student to attain the desired degree (Wächter et al., 2015). The abovementioned metric has drawn increased public policy attention since its elongation involves substantial costs for stakeholders in terms of foregone earnings and additional tuition expenditures (Bound, Lovenheim, \& Turner, 2010). Any delay in degree completion represents a waste of resources both at individual and at collective level, thus affecting the returns to investment in higher education (Casalone \& Orientale, 2011). Among researchers, however, the length of time to degree attainment has received little attention. It is identified that student flow processes include:

1. Learning time: This component is the amount of time it takes the student to complete successfully a learning activity.

2. Scheduling time: This component is the amount of time from when a procedure is scheduled until it actually takes place e.g. internship approval

3. Teaching and processing time: this component is the time it takes to perform a service e.g. a computer networking lab, thesis or assignment supervision.

4. Assessment and examination reporting time: The component is the time it takes from exam application to grade announcement. 
5. Registration time: This component is the amount of time it takes the undecided or undeclared student to select and complete the registration for a specific pathway (major, specialization field etc.).

The complexity and uncertainty of academic processes bring about different issues such as prolonged education periods, inefficient use of HEI resources, and unbalanced course or staff scheduling (Shulock \& Koester, 2014). Prolonged education periods, are constituted by delays in pathway selections, excess courses, failures in "roadblock" courses, facility constraints especially for courses that have laboratory requirements, advising and scheduling bottlenecks (Jenkins \& Cho, 2013). Therefore, an alternative for improving the performance of a specific department can make changes in metrics for student success such as time to completion and in the student flows. These changes may include eliminating unnecessary activities and identifying alternative process flows. By doing this, some operations research methods like CPM and PERT can help department director.

This study is conducted in a University's Division of Lifelong Learning to understand the student flow of a specific program with respect to the FCPM and FPERT. The reason for incorporating fuzzy sets is stemmed from that fuzzy numbers are more effective for high uncertainty processes as in education. Activities affecting student flow through the learning pathways are identified and network flow diagram is drawn. 72 student's data about the times of each activities are obtained from the observed program. Findings through application of these methods, the expected time for completion of the program, the critical path and slack times are determined.

The rest of the paper is organized as follows: Section 2 presents related literature while section 3 presents an overview of CPM and PERT methods alongside with their fuzzy versions. Section 4 deals with our case study in a lifelong learning department of a university, which offers a training program for the Cisco associate-level certification. Finally, our conclusions and limitation of the study are presented in section 5 as well as some suggestions for future works.

\section{Literature review:}

A HEI has to perform an amount of processes and develop a variety of procedures both to ensure the fulfillment of its duties and to improve the abovementioned rates. These processes and procedures are multifaceted (Tam, 2010) and raise constant challenges to management and administration at different levels (Ibrahim, 2015) (Iatrellis, Kameas, \& Fitsilis, 2019). From student's perspective, educational processes, especially those belonging to the higher educational sector, are acknowledged as complex and characterized by the plethora of academic choices, the local constraints, the student's needs and the dynamic nature of the defining personalized educational goals (Vizcarro 
\& Vos, 2002) (Iatrellis, Kameas, \& Fitsilis, 2017). Of course, process complexity is not unique in education. Other industries have processes that are every bit as complex and sometimes they are spread across large geographic areas and shorter or longer periods of time.

Nevertheless, PERT/CPM as well as their fuzzy versions are not used in education. A review of the literature uncovered only few instances of PERT/CPM in education and that used PERT/CPM for curriculum design and management; there was no attempt to change the processes of education.

\section{Methods:}

\subsection{CPM and PERT}

CPM and PERT are the two of contemporary planning and scheduling techniques that are widely used in the programming of projects. CPM assumes that activity durations are known with certainty. However, PERT assumes that activity durations are random variables (i.e. probabilistic). The first step in CPM/PERT is to construct a project network. In an activity-on-the-node network format, project activities are represented by nodes and precedence relations by arcs between the nodes. Figure 1 displays a precedence relation between two activities in an activity-on-the-node format. It is said that activity 2 is a successor of activity 1 and activity 1 is a predecessor of activity 2 .

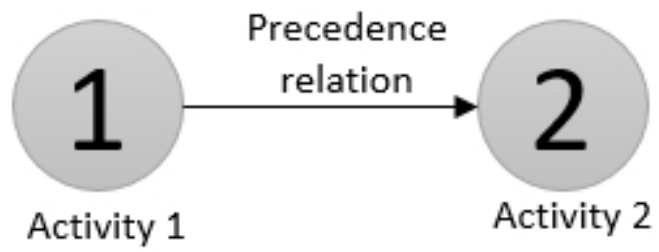

Figure 1: An example activity link in activity-on-the-node format

In an activity-on-the-arc network format, project activities are represented by arcs, as shown in figure 2 . The nodes are events (or milestones) denoting the start and/or finish of a set of activities of the project and implicitly model the precedence relations between the nodes.

Event 1

Event 2

Event 3

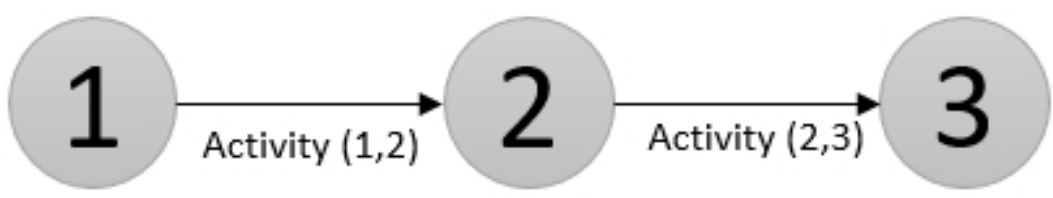

Figure 2: An example activity link in activity-on-the-arc format 
The duration of the project is determined by the length of the critical path, which is the longest path of the network chart and consists entirely of critical nodes. The critical path can be identified by determining the following parameters for each task:

1. Earliest Start Time (ES): the earliest time at which the task can start, given that any predecessor tasks must be completed first.

2. Earliest Finish Time (EF): the earliest start time for the task plus the time required to complete the task.

3. Latest Finish Time (LF): the latest time at which the task can be completed without delaying the project.

4. Latest Start Time (LS): the latest finish time minus the time required to complete the task.

The slack time or float for a task is the time between its earliest and latest start time, or between its earliest and latest finish time, or, to put it another way, slack is the amount of time that a task can be delayed past its earliest start or earliest finish without delaying the project. If the earliest and latest end times are the same, the task is critical. The critical path is the path through the network in which none of the tasks have slack, that is, the path for which $\mathrm{ES}=\mathrm{LS}$ and $\mathrm{EF}=\mathrm{LF}$ for all tasks in the path. Any delay in the critical path delays the whole project. In order to reduce the duration of the project, it is necessary to reduce the total time required for the activities in the critical path.

A distinguishing feature of PERT is its ability to deal with uncertainty in activity completion times. For each activity, the model usually includes three time estimates:

a. Optimistic time to

b. Most likely time $t_{m}$

c. Pessimistic time $t_{p}$

The expected activity time ( $\left.\mathrm{t}_{\mathrm{e}}\right)$ of a specific activity is calculated as in

$$
t_{e}=\frac{\mathrm{t}_{0}+4 t_{m}+t_{p}}{6}
$$

The variance for each is given by (2):

$$
\sigma^{2}=\left(\frac{t_{p}-t_{0}}{6}\right)^{2}
$$

The completion time is determined by adding the times for the activities in each sequence. The project standard deviation can be calculated by determining the square root of the sum of the PERT variances. Eventually, a HEI decision maker can obtain the probability of completion before a specified date, the critical path activities that directly impact the completion time, the activities that have slack time and that can lend resources to critical path activities and the activities start and end dates (Trietsch \& Baker, 2011). 


\subsection{Fuzzy versions of CPM and PERT:}

Before explaining the steps of FCPM and FPERT, it is useful to review the fuzzy set theory, as developed by Zadeh (Zadeh, 1965), and the concept of fuzzy numbers persented by Dubois and Prade (Dubois \& Prade, 2007). In a universe of discourse $X$, a fuzzy subset $A$ of $X$ is characterized by a membership function $\mathrm{fA}(\mathrm{x})$ which associates with each element $\mathrm{x}$ in $\mathrm{X}$ a real number in the interval $[0,1]$. The function value $f A(x)$ represents the grade of membership of $\mathrm{x}$ in $\mathrm{A}$. The larger $\mathrm{fA}(\mathrm{x})$ the stronger the degree of belongingness for $\mathrm{x}$ in $\mathrm{A}$.

A fuzzy number A (Dubois \& Prade, 2007) in R (real line) is a trapezoidal fuzzy number if its membership function $\mathrm{fA}(\mathrm{x})$ is as in (3)

$$
f_{A}(x)= \begin{cases}\frac{x-c}{a-c}, & c \leq x \leq a \\ 1 & a \leq x \leq b \\ \frac{x-d}{b-d}, & b \leq x \leq d \\ 0, & \text { otherwise }\end{cases}
$$

with $-\infty<\mathrm{c} \leq \mathrm{a} \leq \mathrm{b} \leq \mathrm{d}<\infty$, the trapezoidal fuzzy number A can be represented by (c, a, b, d). Using this function, it is possible to assign a membership degree to each of the element in the universe of discourse X. Elements of the set could but are not required to be numbers as long as a degree of membership can be deduced from them. It is important to note the fact that membership grades are not probabilities since there is no requirement for their summation to be equal to 1 .

A trapezoidal fuzzy number A of the universe of discourse $\mathrm{X}$ can be characterized by a trapezoidal membership function parameterized by a quadruple (c ,a,b,d) as shown in Fig 3, where a , b, c and d are real values.

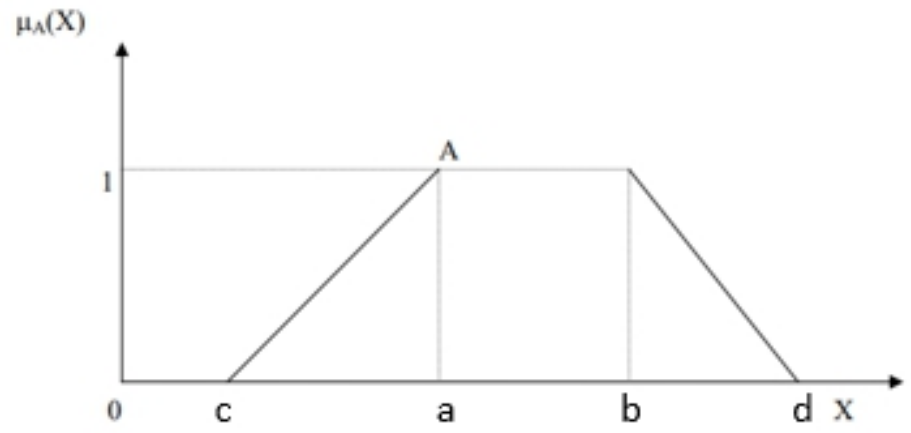

Fig.3 Membership function of trapezoidal fuzzy number A

From Fig.3, we can see that if $\mathrm{c}=\mathrm{a}$ and $\mathrm{b}=\mathrm{d}$, then $\mathrm{A}$ is called a crisp interval; if $\mathrm{c}=\mathrm{a}=\mathrm{b}=\mathrm{d}$, then $\mathrm{A}$ is a crisp value. In Fig.4, if $\mathrm{a}=\mathrm{b}$, then $\mathrm{A}$ becomes a triangular fuzzy number as shown in Fig.3, and it can be parameterized by a triplet ( $\mathrm{c}, \mathrm{a}, \mathrm{d})$. 


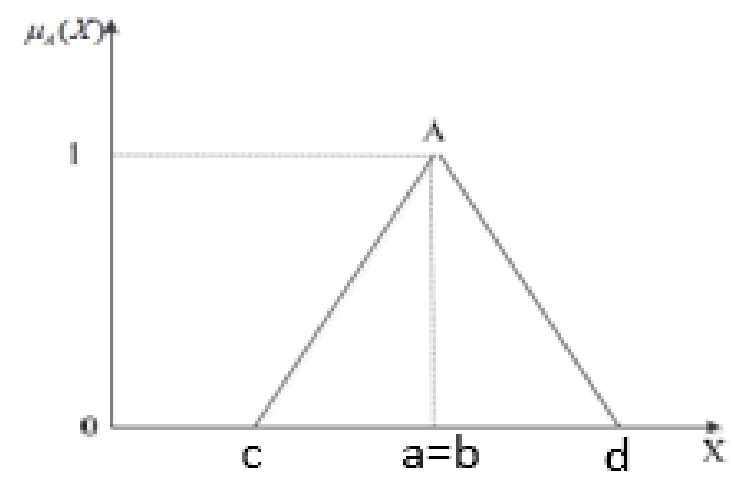

Fig.4 Membership function of triangular fuzzy number $A$

By the extension principle [20], the extended algebraic operations of any two trapezoidal fuzzy numbers $\mathrm{A} 1=(\mathrm{c} 1, \mathrm{a} 1, \mathrm{~b} 1, \mathrm{~d} 1)$ and $\mathrm{A} 2=(\mathrm{c} 2, \mathrm{a} 2, \mathrm{~b} 2$, d2) can be expressed as:

Addition $\oplus$ :

$\mathrm{A} 1 \oplus \mathrm{A} 2=(\mathrm{c} 1, \mathrm{a} 1, \mathrm{~b} 1, \mathrm{~d} 1) \oplus(\mathrm{c} 2, \mathrm{a} 2, \mathrm{~b} 2, \mathrm{~d} 2)=(\mathrm{c} 1+\mathrm{c} 2, \mathrm{a} 1+\mathrm{a} 2, \mathrm{~b} 1+\mathrm{b} 2$, $\mathrm{d} 1+\mathrm{d} 2)$

Subtraction $\Theta$ :

$\mathrm{A} 1 \Theta \mathrm{A} 2=(\mathrm{c} 1, \mathrm{a} 1, \mathrm{~b} 1, \mathrm{~d} 1) \Theta(\mathrm{c} 2, \mathrm{a} 2, \mathrm{~b} 2, \mathrm{~d} 2)=(\mathrm{c} 1-\mathrm{d} 2, \mathrm{a} 1-\mathrm{b} 2, \mathrm{~b} 1-\mathrm{a} 2, \mathrm{~d} 1$ $-\mathrm{c} 2)$

The notation and process steps of FCPM are given in the following [13-16,18]:

\section{Notation:}

$N$ : The set of all nodes in a project network

Aij : The activity between nodes $i$ and $j$

FETij : The fuzzy activity time of $A i j$

$F E S j$ : The earliest fuzzy time of node $j$

$E L F j$ : The latest fuzzy time of node $j$

FTSij : The total slack fuzzy time of $A i j$

$S(j)$ : The set of all successor activities of node $j$

$N S(j)$ : The set of all nodes connected to all successor activities of node $j$, i.e., $N S(j)=\{k \mid A j k \in S(j), k \in N\}$

$F(j)$ : The set of all predecessor activities of node $j$

$N P(j)$ : The set of all nodes connected to all predecessor activities of node $j$, i.e.,

$N P(j)=\{i \mid A i j \in F(j), i \in N\}$

$F C P M(P k)$ : The fuzzy completion time of path $P k$ in a project network.

Steps of FCPM

Fuzzy critical path analysis algorithm:

1. Identify activities in a project.

2. Establish precedence relationships of all activities. 
3. Estimate the fuzzy activity time with respect to each activity.

4. Construct the project network.

5. Calculate $\beta$ that means risk factor for each $A_{i j}$ with (6).

$$
\boldsymbol{\beta}=\sum_{i} \sum_{j}\left(\frac{\left(a_{i j}-c_{i j}\right)}{\left(a_{i j}-c_{i j}\right)+\left(d_{i j}-b_{i j}\right)}\right) / t
$$

where $t$ denotes the set of all actives and the number of actives in a project network, respectively.

6. Let $F E S 1=(0,0,0,0)$ and calculate $F E S j, j=2,3, \ldots, n$, by using property:

$F E S j=\max \{F E S i \oplus F E T i j \mid i \in N P(j), j \neq 1, j \in N\}$

7. Let $F L F n=F E S n$ and calculate $F L F j, j=n-1, n-2, \ldots, 2$, 1, by using property

$$
F L F j=\min \{F L F k \Theta F E T j k \mid k \in N S(j), j \neq n, j \in N\}
$$

8. Calculate FTSij with respect to each activity in a project network by using property

$$
F T S i j=F L F j_{-}(\text {FESi } \oplus \text { FETij }), 1 \leq i<j \leq n ; i, j \in N
$$

9. Find all the possible paths and calculate $F C P M(P k)$ by using property

$$
\boldsymbol{n F T S}_{i j} \in \boldsymbol{P}
$$

$$
\operatorname{FCPM}\left(P_{k}\right)=\sum_{i, j \in P_{k}} 1 \leq i<j \leq
$$

10. Find the fuzzy critical path by using definition (11) and theorem (12). Assume that there exists a path $P C$ in a project network such that

$$
F C P M(P C)=\min \{F C P M(P i) \mid P i \in P\}
$$

then the path $P C$ is a fuzzy critical path.

Assume that the fuzzy activity times of all activities in a project network are trapezoidal fuzzy numbers, then there exists fuzzy critical path in the project network.

11. Higher education decision makers can learn the probability that the project will be completed by a specified time using (13)

$Z=\frac{\mathrm{X}-\mu}{\sigma}$

\section{Application case:}

The application is performed in a university's lifelong learning division. The university of Applied Sciences of Thessaly offers the Cisco Networking Academy program $(\mathrm{CP})$ and prepares students for the widely accepted Cisco Associate-level certification. Candidates begin with Cisco Certified Entry Level Technician (CCENT) certification as an interim step to the Associate-level (see Fig. 5). A sample of 72 learners' data is used. The data 
is gathered through the university student information management system, interviews and direct observation method. The learner flow of the CP is as follows:

Candidates pursuing the CCENT can study on campus or at a distance. The first option is designed for both in-class and self-paced study and is divided into an introductory and a main module, while the second option provides a completely self-study pathway, which includes virtual learning instructor-led demonstrations and visual presentations. After obtaining the CCENT credential, which is a prerequisite for associate-level credentials, learners need to choose from several certification pathways, including cloud, collaboration, cyber ops, data center, industrial, routing and switching, security, service provider and wireless. An academic advisor is available to assist learners with selecting the best track for both the CP program and meeting their future career goals. Learners who successfully complete the training are eligible to earn Cisco Associate-level certification by passing one or two certification exams, depending on the track they choose. Finally, learners can complete the CP program and exit with three different ways: 1) leaving from university 2) register to a different lifelong program offered by the university, and 3) continue on the Professional level of CISCO certifications track.

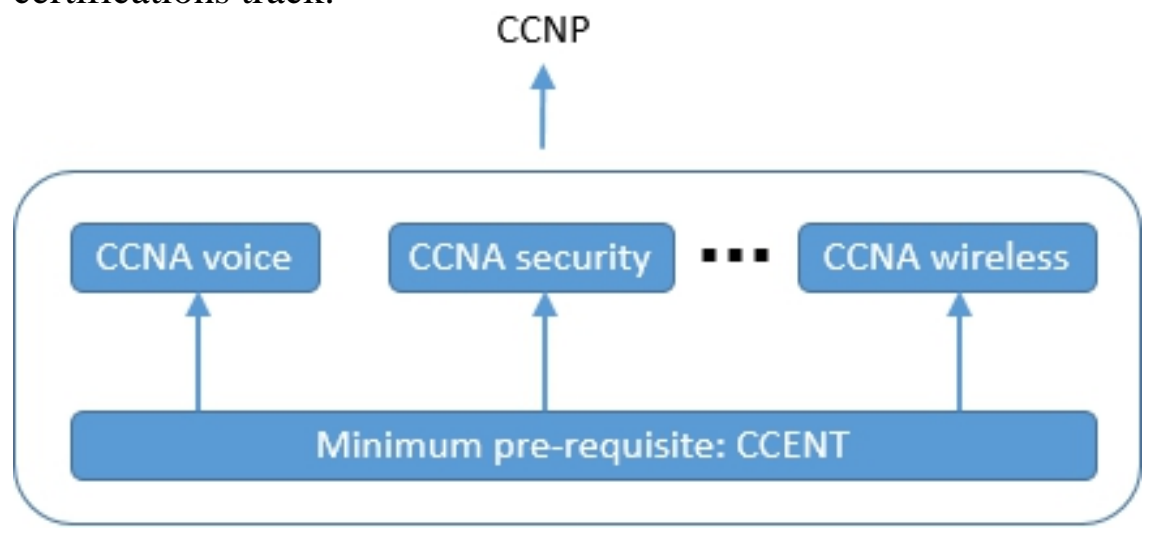

Fig.5 Cisco certification pathways

The activities of the CP learner flow are identified as shown in Table 1. The fuzzy activity times of the project and the project network chart are shown in Table 2 and Figure 6, respectively. In this paper, the fuzzy activity time is presented by trapezoidal fuzzy numbers (Han, Chung, \& Liang, 2006), where $a_{i j}$ and $d_{i j}$ are minimum and maximum values of accessing activity time for $A_{i j}$, whereas $b_{i j}$ and $c_{i j}$ are the first quartile and third quartile of activity time for $\mathrm{A}_{\mathrm{ij}}$. If there is only one set of four historical data, the $\mathrm{a}_{\mathrm{ij}}, \mathrm{b}_{\mathrm{ij}}, \mathrm{c}_{\mathrm{ij}}$ and $\mathrm{d}_{\mathrm{ij}}$ can be sorted from minimum to maximum. Conversely, if one has no further information with respect to activity $A_{i j}$, the fuzzy activity $F_{A T} T_{i j}=\left(a_{i j}, b_{i j}, c_{i j}, d_{i j}\right)$ 
can be evaluated subjectively by the CP decision maker based on his/her subjective judgement and experience.

Table 1. Activities of the CP

\begin{tabular}{|c|c|}
\hline Symbol & Activity \\
\hline A & Completing distance learning package (CCENT certification) \\
\hline B & $\begin{array}{l}\text { Completing on campus introductory training "computer basics" (in-class or } \\
\text { self-paced) }\end{array}$ \\
\hline $\mathrm{C}$ & Completing on campus CCENT training (in-class or self-paced) \\
\hline $\mathrm{D}$ & EXAM (CCENT certification) \\
\hline $\mathrm{E}$ & $\begin{array}{l}\text { Academic Advising Services assisting and supporting learners in exploring } \\
\text { available tracks and through the registration process }\end{array}$ \\
\hline $\mathrm{F}$ & Selecting a Cisco Associate-level track \\
\hline G & Completing training courses (Cisco Associate-level certification) \\
\hline $\mathrm{H}$ & EXAM (Cisco Associate-level certification) \\
\hline I & Transferring to another lifelong program offered by the institution \\
\hline $\mathrm{J}$ & Registration \\
\hline $\mathrm{K}$ & Terminating enrollment \\
\hline $\mathrm{L}$ & Continue on the CCNP certification track \\
\hline
\end{tabular}

Table 2. FETs for each activity of the CP

\begin{tabular}{llllll}
\hline Activity & Predecessor & FATs (in days) & & \\
\hline A & - & 30 & 40 & 55 & 110 \\
B & - & 5 & 7 & 9 & 20 \\
C & B & 24 & 29 & 26 & 65 \\
D & A, C & 3 & 5 & 9 & 13 \\
E & D & 4 & 5 & 8 & 14 \\
F & D & 8 & 15 & 28 & 134 \\
G & E, F & 90 & 150 & 280 & 411 \\
H & G & 14 & 20 & 26 & 36 \\
I & H & 5 & 6 & 8 & 9 \\
J & H & 5 & 8 & 8 & 14 \\
K & I & 1 & 2 & 3 & 5 \\
\hline
\end{tabular}

Fig.6 Project network chart of the CP

By using the equations in the related section above, EFT, LFT values of each note are determined as shown in Table 3.

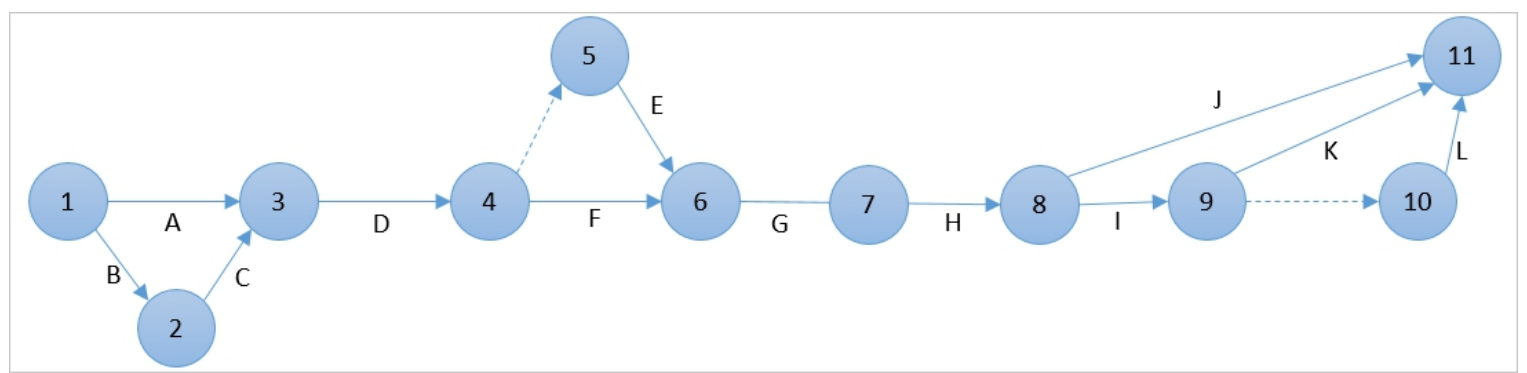


Table 3. FES and FLF of each node

\begin{tabular}{lllllllll}
\hline Node & \multicolumn{9}{l}{ FES values } & \multicolumn{7}{c}{ FLF Values } \\
\hline 1 & 0 & 0 & 0 & 0 & -653 & -223 & 99 & 457 \\
2 & 5 & 7 & 9 & 20 & -543 & -168 & 139 & 487 \\
3 & 5 & 7 & 9 & 20 & -478 & -142 & 168 & 511 \\
4 & 8 & 12 & 18 & 33 & -465 & -133 & 173 & 514 \\
5 & 8 & 12 & 18 & 33 & -345 & -113 & 183 & 518 \\
6 & 16 & 27 & 46 & 167 & -331 & -105 & 188 & 522 \\
7 & 106 & 177 & 326 & 578 & 80 & 175 & 338 & 612 \\
8 & 120 & 197 & 352 & 614 & 116 & 201 & 358 & 626 \\
9 & 125 & 203 & 360 & 623 & 125 & 206 & 364 & 630 \\
10 & 125 & 203 & 360 & 623 & 122 & 203 & 360 & 626 \\
11 & 130 & 209 & 366 & 631 & 130 & 209 & 366 & 631 \\
\hline
\end{tabular}

Then total FTSs are calculated for each activity with (9) and shown in table 4:

Table 4. FTS of each node

\begin{tabular}{lllll}
\hline Node & FTS values & & & \\
\hline 1 & -563 & -168 & 139 & 487 \\
2 & -588 & -197 & 128 & 481 \\
3 & -543 & -799 & -227 & 278 \\
4 & -498 & -151 & 161 & 506 \\
5 & -498 & -151 & 161 & 506 \\
6 & -378 & -131 & 171 & 510 \\
7 & 106 & 177 & 326 & 578 \\
8 & -498 & -151 & 161 & 506 \\
9 & -498 & -154 & 161 & 505 \\
10 & -498 & -151 & 161 & 506 \\
11 & 130 & 209 & 366 & 631 \\
\hline
\end{tabular}

All possible paths are found and FCPMs for each one are calculated with (10). They compared and FCPM ( $\left.\mathrm{P}_{\mathrm{i}}\right)$ is obtained. FCON and $\mathrm{R}\left(\mathrm{FCPM}\left(\mathrm{P}_{\mathrm{i}}\right)\right)$ values of each possible path are shown in table 5 .

Table 5. FCPM and R(FCPM (Pi)) values of each possible path

\begin{tabular}{lllllll}
\hline$\#$ & Possible paths & \multicolumn{2}{l}{ FCPM $(\mathrm{Pi})$} & & \\
\hline 1 & $1-3-4-5-6-7-8-9-11$ & -2354 & -607 & 1108 & 3086 & 0,123492581 \\
2 & $1-3-4-5-6-7-8-11$ & -2855 & -764 & 1265 & 3587 & 0,022335678 \\
3 & $1-3-4-5-6-7-8-9-10-11$ & -2357 & -610 & 1104 & 3082 & 0,085119622 \\
4 & $1-3-4-6-7-8-9-11$ & -2972 & -781 & 1259 & 3587 & 0,014604829 \\
5 & $1-3-4-6-7-8-11$ & -2474 & -624 & 1098 & 3083 & 0,015223527 \\
6 & $1-3-4-6-7-8-9-10-11$ & -2975 & -784 & 1255 & 3583 & 0,088913013 \\
7 & $1-2-3-4-5-6-7-8-9-11$ & -3370 & -1531 & 1053 & 3875 & 0,364872082 \\
8 & $1-2-3-4-5-6-7-8-11$ & -2872 & -1374 & 892 & 3371 & 0,054279849 \\
9 & $1-2-3-4-5-6-7-8-9-10-$ & -3373 & -1534 & 1049 & 3871 & 0,013983146 \\
& 11 & & & & & \\
10 & $1-2-3-4-6-7-8-9-11$ & -2992 & -1394 & 882 & 3367 & 0,020546752 \\
11 & $1-2-3-4-6-7-8-11$ & -2992 & -1394 & 882 & 3367 & 0,004323685 \\
12 & $1-2-3-4-6-7-8-9-10-11$ & -2995 & -1403 & 878 & 3361 & 0,013367419 \\
\hline
\end{tabular}


As a result, $\mathrm{R}\left(\mathrm{FCPM}\left(\mathrm{P}_{11}\right)\right)$ has minimum value among all possible paths' FCPMs. So, the critical path is 1-2-3-4-5-6-7-8-11 in this case. Time to completion period is approximately between 209 and 366 days i.e. (130, 209, 366, 631).

The activities on the critical path are: B (Completing on campus introductory training "computer basics"), C (Completing on campus CCENT training), D (EXAM), E (Academic Advising Services), G (Completing training courses), I (Transferring to another lifelong program offered by the institution), $\mathrm{K}$ (Terminating enrollment). As important activities do not permit any flexibility in scheduling, any delay in any of the important activities B, C, $\mathrm{D}, \mathrm{E}, \mathrm{G}, \mathrm{I}$ or $\mathrm{K}$ will delay the whole $\mathrm{CP}$ flow process.

Mean values and standard deviation which is calculated based on the total $\mu$ and $\sigma$ values of the activities on the critical path are determined as $\mu=480.452, \sigma=180.34$

\section{Conclusion}

The need to embrace economic policies has become inevitable in higher education sector. In order to reduce the unnecessary delays, eliminate unnecessary activities and optimize process flows in education, operations methods like CPM and PERT can play an important mission. Since deterministic approaches cannot afford to complex projects, fuzzy versions of CPM and PERT are applied in this study. A case study is carried out in a university to understand the student flow of the department for a specific program of study. Activities affecting student flow through the learning pathways are identified and project network is drawn. 72 students' data about the times of each activities are used in the analysis. Findings through application case, the expected time for completion of the project, slack times and the critical path are determined.

\section{References:}

1. Bound, J., Lovenheim, M., \& Turner, S. (2010). Increasing Time to Baccalaureate Degree in the United States. Population Studies Center, University of Michigan, Institute for Social Research.

2. Casalone, G., \& Orientale, P. (2011). Does time-to-degree matter? The effect of delayed graduation on employment. AlmaLaurea InterUniversity Consortium.

3. Dubois, D., \& Prade, H. (2007). International Journal of Systems Science Operations on fuzzy numbers. International Journal of System Science, $9((6)), \quad 613-626$. https://doi.org/10.1080/00207721.2010.492663

4. Han, T., Chung, C., \& Liang, G. (2006). Application of Fuzzy Critical Path Method To Airport'S Cargo Ground Operation Systems. 
Science, 14(3), 139-146.

5. Iatrellis, O., Kameas. Achilles, \& Panos, F. (2019). A novel integrated approach to the execution of personalized and self-evolving learning pathways. Educ Inf Technol (2019) 24:781-803, 24(ISSN 1360-2357). https://doi.org/10.1007/s10639-018-9802-7

6. Iatrellis, O., Kameas, A., \& Fitsilis, P. (2017). Academic Advising Systems: A Systematic Literature Review of Empirical Evidence. Education Sciences, 7(4), 90. https://doi.org/10.3390/educsci7040090

7. Iatrellis, O., Kameas, A., \& Fitsilis, P. (2019). EDUC8 ontology: semantic modeling of multi-facet learning pathways. Educ Inf Technol (2019). https://doi.org/10.1007/s10639-019-09877-4

8. Ibrahim, N. G. (2015). Process Improvement in Higher Education Institutions, (May).

9. Jenkins, D., \& Cho, S.-W. (2013). Get With the Program ... and Finish It: Building Guided Pathways to Accelerate Student Completion. New Directions for Community Colleges, 2013(164), 27-35. https://doi.org/10.1002/cc

10. Lane, A. (2014). Placing Students at the Heart of the Iron Triangle and the Interaction Equivalence Theorem Models. Journal of Interactive Media in Education, 2014(2), Art. 5. https://doi.org/10.5334/jime.ac

11. Munns, A., \& Bjeirmi, B. F. (1996). The role of project management in achieving project success. International Journal of Project Management, $14(2)$, 81-87. https://doi.org/http://dx.doi.org/10.1016/0263-7863(95)00057-7

12. Project Management Institute Inc. (2000). A guide to the project management body of knowledge (PMBOK® guide). Book. https://doi.org/10.5860/CHOICE.34-1636

13. Serrano, S. C., \& Avilés, R. A. (2018). Project management techniques at the Complutense University: academic librarians' perceptions. New Review of Academic Librarianship, 4533(January). https://doi.org/10.1080/13614533.2017.1406378

14. Shulock, N., \& Koester, J. (2014). Maximizing resources for student success by reducing time- and credits-to-degree, (July). Retrieved from http://hcmstrategists.com/maximizingresources/images/Maximizing_ Resources_Paper.pdf

15. Tam, M. (2010). Quality in Higher Education Measuring Quality and Performance in Higher Education Measuring Quality and Performance in Higher Education, (May 2013), 37-41. https://doi.org/10.1080/1353832012004507

16. Trietsch, D., \& Baker, K. (2011). PERT 21: Fitting PERT/CPM for Use in the 21 st Century. International Journal of Project Management, (September). 
17. Vizcarro, C., \& Vos, H. (2002). New developments in the assessment of learning: where are we? International Journal of Continuing Engineering Education and Life Long Learning, 12, 1-30.

18. Wächter, B., Kelo, M., Lam, Q. K. H., Effertz, P., Jost, C., \& Kottowski, S. (2015). University quality indicators: a critical assessment. Retrieved from http://www.europarl.europa.eu

19. Zadeh, L. a. (1965). Fuzzy sets. Information and Control, 8(3), 338353. https://doi.org/10.1016/S0019-9958(65)90241-X. 